\title{
Innovation and skill dynamics: a life-cycle approach
}

\author{
Francesco Vona* and Davide Consoli**,ं
}

\begin{abstract}
This article focuses on the institutional adjustments that facilitate the routinization of technological opportunities. We propose a life-cycle approach that accounts for the emergence, development, and transformation of new knowledge with special emphasis on the role of adaptive educational and training systems for the diffusion of skills that complement new technology. The article reconciles two empirical phenomena associated with radical technological breakthroughs: changes in the skill content within occupations and the process of knowledge systematization underpinning the adaptation of education and training. We claim that systematization is a crucial, but largely overlooked, element in the study of skill mismatches, inequalities, and successful takeoff of new technologies.
\end{abstract}

JEL Classification: J24, D8, 031.

\section{Introduction}

This article focuses on the institutional pathways that, by enabling the systematization of practical knowledge, favor the diffusion of innovation. Our goal is to articulate in detail the link between the emergence of new skills closely tied to radical new technology and the adjustments that are made in formal education to reap the potential benefits of innovation. For definitional purposes, we propose that skills are a combination of capacity to learn and know-how applied to a specific task in a specific context. Through a "life-cycle" heuristic, we capture the dynamic nature of know-how, that is, the emergence, development, and transformation of new skills and the process of knowledge systematization underpinning the adaptation of education and training.

\footnotetext{
${ }^{*}$ Francesco Vona, OFCE (Observatoire Français des Conjonctures Économiques) and SKEMA Business School, Sophia AntipolisCedex, France. e-mail: francesco.vona@sciencespo.fr

${ }^{\star *}$ Davide Consoli, INGENIO (CSIC-UPV), Valencia, Spain. e-mail: davide.consoli@ingenio.upv.es ${ }^{\dagger}$ Main author for correspondence.
} 
Our discussion draws heavily from the recent experience of information and communication technologies (ICTs) and the radical innovations that these general purpose technologies have brought about (Bresnahan and Trajtenberg, 1995; Brynjolfsson and Hitt, 2000; David, 2001). While the competitive and organizational aspects of this trajectory have been debated in great detail, the scholarly literature has somewhat neglected the institutional responses that proved crucial for large-scale adoption of ICTs. The article documents the importance of this process by discussing historical instances of new formal training that has grown out of repeated practice associated with the use of new technology.

Building on the seminal contribution of Nelson and Phelps (1966), we propose skill systematization as a conceptual device to connect technology, institutions, and human capital. Under this heuristic, we bring together insights from different streams of scholarly research. First, we make reference to the literature on the enabling role of institutional infrastructure for increasing returns and innovation (Nelson, 1994; David and Wright, 1997). We then connect the latter with the work on knowledge economics and cognitive comparative advantage to call attention to important subtleties of the division of labor (Langlois, 2003; Levy and Murnarne, 2004). This connection is the basis for our skill-life heuristic. Subsequently we focus on "knowledge systematization", that is, standardization of novel best practices and to their diffusion by means of changes in the content of education and training (Rosenberg, 1976, 1998). Lastly, we outline implementation challenges and policy implications related to skills and innovation, with particular emphasis on the consequences of different forms of institutional adjustment for productivity and labor market inequality.

The article is organized as follows. Section 2 connects strands in the literature on skills, education, and innovation with a view to propose a unified skills life-cycle framework. Section 3 examines knowledge systematization based on the importance of new academic disciplines and training programs for technical change. Section 4 discusses the implications of various adjustment mechanisms related to innovation, productivity, and wage inequality. Section 5 proposes an agenda for future empirical research.

\section{Innovation and skills dynamics}

The seminal work by Nelson and Phelps (1966) provides a classic starting point to a description of the interplay between skill dynamics and technological change. ${ }^{1}$

\footnotetext{
${ }^{1}$ The human capital theory developed by Gary Becker (1993) treats workers' abilities as a continuous and unidimensional variable. While this shortcut is certainly useful in empirical studies on wages, test scores, and educational outcomes, among other things, it does not acknowledge the discontinuity in the process of skill formation which is crucial to understand the dynamic impact of innovation on skills.
} 
The greater capacity for learning possessed by highly educated individuals facilitates the adoption of innovation, especially at early stages when the knowledge related to new technology is ill-defined. Subsequent works inspired by Nelson and Phelps portray the learning process associated to the development of new technology as a somewhat mechanical response. ${ }^{2}$ This view clearly downplays the role of policies and institutions that foster the adaptation of know-how to a changing technology frontier. It seems implausible that the skill threshold falls mechanically just because new technology becomes more widely available. Rather, we argue, possessing adequate skills can be a prerequisite for the adoption of new technology and, hence, to stay close to the frontier. By the same token, rather than being unidirectional, as maintained by the extant approach, the relation between skills and innovation is mediated in important, but so far little appreciated, ways by education. The remainder of this section draws on different strands of literature to establish the connection between skill, technology, and education.

\subsection{Skill dynamics and innovation}

A cursory exploration of the literature on tacit and codified knowledge provides useful insights into the innovation-skills relationship. Knowledge tightly associated to new technology, especially with radical technology, is mostly tacit, sticky and likely to be at the frontier of the particular cognitive domain (Baumol, 2002). Since tacit knowledge is difficult to transfer in the absence of personal interactions-at school or in the workplace (Nelson and Winter, 1982), at early stages of technological development, knowledge transfer is reliant on the mobility of only a few talented individuals. Subsequently, incremental improvements perfect the content and assignment of work tasks and facilitate the adoption of routines that lower barriers to use. While imbalances in the distribution of knowledge among agents provide the right incentives to explore the new paradigm, coordinated efforts to systematize new knowledge facilitate the diffusion of skills and pave the way to a cascade of new innovation opportunities. We argue that in focusing on firms, inventors, and elite research institutions, innovation scholars have neglected the dynamic of skills and the key role of educational institutions.

The research strand inspired by scholarly work on cognitive comparative advantage and artificial intelligence (Simon, 1960) offers useful insights to address this shortcoming. Building on it, labor economists have reframed the relation between humans and "machines" in terms of the dynamics of the skills content of occupations (Autor et al., 2003). The main argument is that humans retain comparative advantage in the elaboration of new ideas, the resolution of novel (i.e. unstructured) problems, and team working; conversely, computers are more efficient in executing

\footnotetext{
${ }^{2}$ See e.g.: Caselli (1999); Aghion et al. (2002); Aghion and Howitt (2004); Krueger and Kumar (2004); Vandenbussche et al. (2006).
} 
clearly specified instructions. As Levy and Murnarne (2004) argue, human workers are better suited to cognitive and interactive nonroutine tasks, compared to machines. ${ }^{3}$ In this perspective, the definition of skills is broader in that it involves "theoretical know-how", problem-searching and problem-solving heuristics, codes for interpretation, and problem framing (Balconi et al. 2007). As a consequence, and to build a bridge with the literature reviewed earlier, "tacitness" is no longer a static conceptual category since theoretical know-how, in principle, can be codified and translated into propositional knowledge (see the classic analysis by Cowan et al., 2000). The study by Autor et al. (2003) on the organization of work in the banking sector is a classic example of how intellectual skills have been replaced by software in the assessment of mortgage applications. ${ }^{4}$

Our central claim is that the purposeful absorption of practical know-how within the formal education is a crucial ingredient for fully exploiting the benefits of new technology. The life-cycle framework outlines this idea.

\subsection{The skills life-cycle and knowledge systematization}

Our life-cycle heuristic draws on the seminal contribution of Langlois (2003) on cognitive comparative advantage in the division of labor. The main idea is that the assignment of work activities to either humans or to machines depends ceteris paribus on the extent to which tasks can be standardized and simplified. At early stages of the diffusion of new technology, activities are complex and "ill-structured", and are the main competence of the few who handle directly the production routines. Their know-how can neither be synthesized nor communicated. Nathan Rosenberg (1976) drew attention to something similar when recounting that in the initial phase of mass production the attendant know-how had more to do with possessing sufficient manual dexterity with the new technique rather than mastering the underlying scientific principles. Over time learning by doing facilitates the identification of regularities, the establishment of conditional rules, and eventually the creation of instructions that are a prerequisite for skill specialization (Simon, 1960; Levy and Murnarne, 2004). At this point, specialized workers enjoy higher productivity levels as they acquire more dexterity while at the same time task standardization makes automation increasingly convenient.

\footnotetext{
${ }^{3}$ The so-called 'routinization hypothesis' (Autor et al., 2006) in this stream of the literature states that computers are better suited to tasks that can be expressed in the form of rules, while humans retain comparative advantage in nonroutine tasks that involve creativity, pattern recognition, expert thinking, complex communication, and social interaction.

${ }^{4}$ Other similar examples are algorithms for playing chess and software to solve complex mathematical problems in symbolic language, such as 'Mathematica'. The recent study of Brynjolfsson and McAfee (2014) documents several other examples of working tasks that can be performed by the new generation of information technologies, such as driving, speech recognition, and basic motor skills.
} 
An important but little appreciated aspect of the skill-technology cycle is the existence of an upper cognitive limit in the productivity gains ensured by a greater division of labor. When this point is reached, tasks are fully standardized, productivity gains from specialization diminish, though capital deepening may still fuel productivity growth, since the innovation potential of the attendant regime has been almost fully exploited. In fact, both deskilling and skill specialization reduce the potential for creativity at the workplace, thus reducing the margin for further innovation opportunities. The observation that routinization enters diminishing innovation returns clearly contradicts the established notion that the degree of substitutability between machines and (heterogeneous) workers-and thus the degree of routinization-is de ipso facto synchronic with the technology cycle. When the technology life-cycle reaches that critical juncture, new opportunities for innovation depend on widening, as opposed to deepening, the knowledge base. We argue that knowledge systematization and the updating of the content of technical training and higher education are important, yet overlooked, routes to pursue further innovation potential.

A cursory look at the history of technology lends support to this line of argument. Much like notable predecessors such as electricity and industrial chemistry, computerization has come about in fits and (some false) starts punctuated by radical transformations across the board, as is typical of large-scale regime transitions (Hughes, 1983; Freeman and Perez, 1988; David, 2001). Indeed "automation" did not occur overnight but rather through three micro-regimes, each facing distinctive implementation challenges and redesign feedback loops (Nightingale, 2000). In the early phases, automation consisted in the integration of control systems within existing production regimes. Once local productivity improvements reached a plateau, the opportunity for economies of scope called for greater integration across different control devices. Thereby, the core of automation shifted toward process continuity and management control, a whole set of new skills, and required the convergence of artifacts and routines from formerly unrelated industries. ${ }^{5}$ In the most recent micro regime of automation, inventive efforts have been directed toward improving the interface between humans and machines through tight coordination between technical, managerial, and interpersonal skills (Butera, 2014). This long-term trajectory resembles that of electricity and industrial chemistry (see Noble, 1977; Rosenberg, 1998) whereby adjustments to the design and the scope of the core technology could not have exerted such radical effects without complementary adaptations in related domains.

To illustrate, the progressive standardization of certain tasks favored the substitution of labor for ICT capital especially among occupations that are intensive in routine task content, and therefore more exposed to the new technology

\footnotetext{
${ }^{5}$ Examples of this abound in the literature. See e.g. the cases of machine tool production (Rosenberg, 1976), mechatronics (Kodama, 1995), or consumer banking (Consoli, 2005).
} 
(Autor et al, 2003; Goos and Manning, 2007). ${ }^{6}$ But ICTs adoption has also increased the demand for nonroutine analytical and interactive skills thus inducing changes in the content of surviving occupations as well as the emergence of entirely new occupations, especially computer-related ones. ${ }^{7}$ This resonates with the historical perspective on the role of new occupations in accommodating the imbalances due to large-scale technological transitions (see Rosenberg, 1976; Hughes, 1983).

While the natural tendency of new radical technologies to become standardized and hence available for broader applications has been widely studied, the institutional mechanisms that enable the formalisation and diffusion of practical know-how and new skills are still unclear. It is not surprising that the juxtaposition of faster skill obsolescence and of skill shortages combined with the inherent complexity of the technology at hand may have been a very serious obstacle for the automation regime in the absence of progressive adaptations in the system that ensures the supply adequate know-how. The key questions are: where did skilled workers come from? And, how did successive cohorts of workers acquire dexterity to use productively the new technology?

We argue that part of the answer lies in better understanding the process that Rosenberg called knowledge systematization, that is, the formalization, articulation, and verification of learned practices into synthetic rules and instructions. Such a process typically begins with a meta-model, that is, a symbolic representation of fundamental principles and the relationships across the relevant physical units. Subsequently, the initial figuring out gleans into the parameterization of physical characteristics of products and process rules to eventually become codified knowhow (Balconi et al., 2007, Yoshikawa, 1993). The other part of the answer concerns the developments that follow up codification. This is where institutional responses in

\footnotetext{
${ }^{6}$ Several studies find that widespread computer adoption is associated with a sharp decline in the demand for jobs based on routine tasks such as bookkeeping, secretarial, middle-management, and nonspecialist blue collar occupations (see, e.g., Autor et al. 2003, 2006; Spitz-Oener, 2006; Goos and Manning, 2007). The impact of computers on labor markets has some commonalities with the deskilling that followed the first Industrial Revolution (e.g. Braverman, 1974). Atack et al. (2004), for example, it shows that the shift from artisanal to factory work organization enabled the substitution of skilled craft workers with unskilled workers during the second half of the XIX century. Similar insights are provided by Lazonick (1990) and Chandler (1977) on the displacement of skills on the shop floor. Evidence on early XX century in the USA also confirms the remarkable impact of significant innovations in task requirements of occupations. For instance, Goldin and Katz (2008) show that the demand for formal skills was relatively higher among establishments that made intensive use of steam power, while Gray (2013) obtains similar findings for the diffusion of electrification.

${ }^{7}$ To give an idea of the magnitude of within-occupation changes, between 1978 and 1990 more than $2 / 3$ of the entries in the US DOT (the dictionary containing detailed information for several years on the skill content of occupations) were revised on the basis of new job requirements.
} 
the remit of education have proven to be of crucial importance in various accounts of technology-driven economic development (Nelson, 1994; Rosenberg and Nelson, 1994; David and Wright, 1997). Updated curricula and new disciplines are key inputs for widening the knowledge base and opening new opportunities in the aftermath of disruptive radical innovations. As argued by Baumol (2004), technological breakthroughs often stem from individual intuition and an ability to think "outside the box", while rigorous technical training is crucial for the exploitation of the latent benefits of these breakthroughs. Also a study by David and Wright (1997) on the mining sector calls attention to the role of public knowledge infrastructure such as specialist education and the US geological survey in favoring "the formation of (...) mutually reinforcing linkages between this sector (...) and the educational system" (p.229). These linkages in turn became a permanent source of increasing returns insofar, as academic-university linkages and systematic updating of higher education curricula paved the way to the development of the chemicals and the petro-chemical industries. The role of educational and training institutions will be analyzed more in detail in the remainder of the article.

\section{Adjustments to the supply of skills, and the role of educational institutions}

The life-cycle heuristic highlights key question regarding the types of institutional adjustments that match the demand for skills along the technology cycle. At early stages, novel and ill-defined concepts are epistemologically remote from the attendant knowledge base but as new ideas are tested in practice and refined through learning-by-using, those that stand the test of selection become the new standards in both technological trajectories and formal education. It is important to clarify that the metaphor of industries, technologies, or skills undergoing changes across stages may evoke a deterministic character of the life-cycle model. This is not the case here. Rather than proposing a predetermined succession of technology, skills, and education, the life-cycle heuristic proposed here elucidates important nuances of specific historical instances without denying the possibility of indeterminate outcomes, or of diverging patterns. More to the point, we observe that after an initial giant leap by the core technology, training and education have a dual role, both as the conveyor of still raw technical specs and also as a pathway for incremental learning that can illuminate unforeseen innovation potential. To be sure, we claim that mismatches emerging as a consequence of radical technological change are different from mismatches associated with incremental innovation. The latter involves the systematization of new skills, while the former entails fine-tuning of existing training and educational programs. The remainder of this section will explore this difference in greater detail. 


\subsection{Background: rethinking the concept of skill mismatch}

The empirical evidence on the effect of GPT on the skill content of occupations lacks a conceptual framework to account for the reabsorption of structural mismatches between education supply and task requirements. In standard theorizing in both the growth and labor literature (e.g. Pissarides, 2000; Aghion and Howitt, 2004; Acemoglu and Autor, 2010), the differences between occupational skill requirements and education supply are unclear, and mismatches at both the "intensive" margin, i.e. within occupations, and the "extensive" margin, i.e. the emergence of new occupations and skills, are not considered. What is more the lack of demarcation between skill requirements and qualifications proffered by standard human capital theory leads to ambiguous conclusions. The claim that formal education adapts seamlessly to the emergence of new skill requirements ${ }^{8}$ stands in open contradiction with phenomena such as education mismatches and over-education (Green and McIntosh, 2007; Organization for Economic Cooperation and Development [OECD], 2009) which are often dismissed as transitory and friction induced. While in standard human capital theory these phenomena merely reflect unobservable skill endowments, i.e. school quality, not accounted for by formal qualifications, assignment theory (Sattinger, 1993) acknowledges the existence of skill mismatches but does not cast them in a dynamic setting. ${ }^{9}$

Our argument is that skills mismatches and qualitative changes in the educational supply are structural features of the diachronic adaptations between technology and education (Amendola and Gaffard, 1988). If changes in skill requirements within occupations and the emergence of new occupations are relevant, education programs to support nascent occupations must have played a more prominent role than the existing literature has hitherto acknowledged. Our life-cycle approach accommodates structural mismatches and suggests that they are difficult to resolve because the gap between existing and new knowledge requires systematization efforts on the part of specialist institutions, including universities. As a result, empirically observed skill mismatches reflect distinct phenomena depending on the stage of the skilltechnology cycle. At the early stage of technology development, the supply of education lags behind the emergence of new skills hence mismatches are structural. Later on, however, education may adapt in a non-homogenous way across institutions and geographical areas, making effective differences in observed qualifications starker.

\footnotetext{
${ }^{8}$ This is what characterizes models based on Nelson and Phelps (1966). See e.g. Caselli (1999) and Aghion et al. (2002). Iacopetta (2010) elaborates a growth model that includes innovations in formal education enabling the diffusion of a new type of human capital. However, the model does not address institutional issues related to the characteristics of innovation in education.

${ }^{9}$ For these reasons, the debate on the effect of skill mismatches on wages is mainly empirical. See, e.g. Allen and Van der Velden (2001), Houston (2005), Di Pietro and Unwin (2006), and Sutherland (2012).
} 
A careful distinction between the qualitative characteristics of occupations and education programs enables exploration of the sources of the skills required for societal development and responds to the life-cycle heuristic. We want to investigate the institutional mechanisms that provide society with the skills needed to produce, utilize, and further develop new technologies. To this end, we distinguish between (i) institutional adjustments in the presence of skills mismatches at the intensive margin, associated mostly with fine-tuning of the supply of skills, and (ii) institutional adjustments in presence of skills mismatches at the extensive margin, mostly radical adjustment involving a profound redefinition of education programs and the emergence of new programs.

\subsection{Institutional adjustments for mismatches at the "intensive" margin}

There is ample literature on the market failures that prevent optimal changes to existing training programs in front of the challenges of modified demand for skills. Examples include constraints on borrowing, which prevent household investment in children's education (Galor and Zeira, 1993), and poaching of skilled workers, which discourages workers and firms from investing in specific training (Acemoglu and Pischke, 1999). Formal training signaling the competences and skills acquired in on-the-job or other training programs, increases workers' incentives to invest in occupation-specific skills (Busemeyer, 2009). From the viewpoint of firms, cooperation among competitors in the provision of industry-specific skills contributes to the definition of training standards and also lowers the costs related to investing in specific skills and information sharing on emerging mismatches.

This is the case in the German apprenticeship system, which is characterized by high levels of non-market coordination and regulated through consensus among employers, trades unions, and the government. Work on Variety of Capitalism (Estevez-Abe et al., 2001) suggests that a set of complementary institutions prevents underinvestment in specific skills. ${ }^{10}$ Continual adjustments to training programs are necessary to meet changing patterns in the demand for skills, especially in the context of adaptive learning systems such as those described by Lundvall and Johnson (1994). Specific forms of institutional response have gained currency in recent years, for example, programs such as vocational education and training (VET) and life-long learning (LLL) provided by firms or inter-industry organizations. ${ }^{11}$ In this dual

\footnotetext{
${ }^{10}$ E.g. collective bargaining constrains external wage offers, reducing the possibility of workers being poached, while employment protection, e.g. firing costs, increases the expected duration of the work relation and the gains from relationship-specific investment. More or less explicit coordination between firms and unions on the one hand, and between competing firms on the other, enables some sharing of the costs of specific training among interested parties.

${ }^{11}$ VET programmes are designed for young people at the beginning of their careers or prior for entry to the labor market; LLL programmes are aimed at reducing skill obsolescence among incumbent workers.
} 
model, vocational training is a bridge between labor, capital, and the state. The existence of "intermediary" institutions, mostly state regulated, limits the detrimental effects of rapid skill obsolescence and of market failures. Within schools, technically oriented programs are typically offered at secondary level, as well as being regularly featured in national tertiary education programs by institutes such as the Dutch hogescholen, Finnish polytechnics, German fachhochschulen, and semi-professional, sector-specific institutions (e.g. Austria and Switzerland, see Kyvik, 2004). Higher education systems based on the coexistence of general and technically oriented types of education emerged in Europe in the early 1960s as a result of local governmentfirm collaborations. The skills taught are tailored to the needs of incumbent firms within particular industries or geographical areas and, therefore, to the specificities of the attendant innovation system. Also, where they are in place, VET and LLL systems receive funds from both public and private sectors, and thus likely to stay well-resourced even during times of crisis (Tether et al, 2005; Toner, 2011).

While in general the dual system is praised for the broad engagement and ownership philosophy, it is also characterized by a thick layer of formal checks aimed at maintaining coherence between national and local needs, and to avoid that the shortterm needs of some firms distort the supply of training. Moreover, career guidance stemming from VET-type of programs exhibits significant variance across regions, as there is no single agency in charge of ensuring homogeneity of skill quality. Lastly, in the actual practice the dual system has been observed to suffer from excessive detachment between learning from apprenticeship and learning from schooling, thus betraying the scope of a system that, at least in principle, is designed to exploit the complementarity between practical and theoretical learning. The current bias toward firms needs is perceived as a serious limit to opportunities for further progression in schooling (CEDEFOP, 2010). On the whole it seems that this type of training system is ill-suited to confront changes in skill demands due to radical new technology. On the one hand, the high fixed costs of codification prevent private organizations from actively promoting knowledge systematization when the cognitive gap between existing and new technologies is large. On the other hand, the smaller priority placed on general education and broad academic skills limits the scope of this institutional response.

\subsection{Institutional adjustments for radical mismatches and new skills}

Knowledge systematization and adaptation of educational curricula are crucial to counter the imbalances generated by radical new technologies. At the institutional level, the transformation of university education consists in the creation of new courses and in changes to existing programs that set the standards for the curricula at lower levels of education. In fact, university education internalizes positive feedbacks from research in different domains (Goldin and Katz, 1999). Higher education institutions (and the scientific community as a whole) are responsible for developing 
new cognitive patterns and categories to encompass practical and localized knowledge in rapidly evolving technological contexts, and aim at widening access to less-talented individuals.

New universities and technical training have some prominence in the historical analysis of industrial innovation, especially when focused on the USA at the end of the XIX century. American higher education institutions, unlike their European counterparts, were modeled from the outset around the practical needs of local industries and the priorities of state legislatures (Geuna, 1999; Rosenberg and Nelson, 1994). The role of the university is recurrent in historical accounts of the transition to factory production where systematic efforts to incorporate useful knowledge responded to the changing demands of large-scale production (Rosenberg, 1976; Noble, 1977). Examples in the USA include the mining and mineral processing industries, which benefited from the provision in universities of engineering training courses at the end of the 1800s (Wright, 1999); chemical and electrical engineering training to supply the chemical, electrical and telecommunication industries (Rosenberg, 1983, 1998); and the proliferation of new teaching around the emerging trajectory of the computer industry (Rosenberg and Nelson, 1994; Mowery and Langlois, 1996).

The common thread is the ascendancy of engineering disciplines that enabled the systematization of new knowledge associated with GPTs and new organizational paradigms. The growing importance of engineering sciences reflects the growing interdependence between scientific knowledge and economic organization (Rosenberg, 1976; Rosenberg and Steinmueller, 2013). We draw attention here to the translational nature of "engineering-type" processes, i.e. of a broad class of task-oriented activities aimed at devising criteria and procedures for a specific goal (Arthur, 2009). The dominant heuristic in these activities is the manipulation of physical, biological, or chemical properties for constructing artificial systems enabling deliberate design and control. Ad hoc feedback mechanisms are crucial for recursive problem solving because scientific knowledge needs be complemented by practical know-how and experience. We suggest that the growth of engineering into several specialized branches is a reflection of the generalized process of knowledge systematization that is central to the skills life-cycle heuristic proposed here. Let us provide a brief overview of the three representative cases.

Consider, first, the transition to factory production, which entailed the development of specialized know-how to meet newly emerged standards for ensuring precision (i.e. controlling, measuring, and correcting) in the mechanized operations required for large-scale production (Rosenberg, 1976; Paulinyi, 1986; Metcalfe, 2002). This process required a responsive machinery-producing industry to correct for technical imbalances, and a system of education and training to provide the necessary skills. Not surprisingly, the emergence of public education was heavily supported by an entrepreneurial class in need of the skills that fitted the new methods of production (Galor et al., 2009). A second instance is the information paradigm 
associated with the computer industry. This process created the need for disciplines that encapsulate practical experience from the pioneer users and developers of new machines, and make it available in forms of general know-how (Mowery and Langlois, 1996; Mowery, 2010). Particularly important in this process are two different institutions: the association of computing machinery (ACM) and new elite universities that pioneered specialized training in computer sciences. ${ }^{12}$ The ACM succeeded in establishing training standards based on trial-and-error adoption of experimental teaching practices and continual expert feedback from peer review on the course content of new programs in computer science (e.g. Davis, 2006). At the same time, Stanford University played a key role in supporting incremental improvements to Integrated Circuit technology, with timely adaptations to its electrical engineering curriculum (Rosenberg, 1983; Harayama, 1998). ${ }^{13}$ Also, the growth of computer science triggered subdisciplines aimed at specialized applications of the computing paradigm. An interesting example is Information Systems which adapted the ICT paradigm to organizations: the knowledge in this field of application is inter-disciplinary in that it combines organization and management theory, core computing skills and the capacity to design and work with datasets. A third instance of knowledge systematization not (at least directly) related to the widespread diffusion of GPTs, is Control Volume Analysis, a training module that was added to the standard aeronautic engineering curriculum in the early 1920s (Vincenti, 1990). This new course content stemmed from the systematic elaboration of specific routines for airplane control that could not be inferred from generic aerodynamics. The codification of these routines, in turn, relied on daily on-the-job interaction within a community of specialists that was not limited to aeronautic engineers, but included a larger group of specialized technicians.

The systematization of localized knowledge into codified instructions and goals along the tracks described above generates two effects. The first is the deepening of engineering knowledge by means of new tools and instruments (e.g. the dynamo, chemical plants) that allow efficient scaling up of production. The second is the abstraction of general principles from newly discovered natural phenomena laying the foundations for novel bodies of basic scientific knowledge. The broad characteristics of "engineering-type" processes, i.e. strong reliance on experience, heuristics, and case studies, and the tendency to develop integrative forms of practical knowledge, apply to other disciplines such as Finance (Norgaard, 1981), Design (Filippetti, 2010), and Business Studies (Whitley, 1988). In several other areas, the recombination of existing knowledge and routines led to the growth of new disciplines such as

\footnotetext{
${ }^{12}$ See the Babbage institute (http://www.cbi.umn.edu/) and issues of the ACM Computing Surveys (e.g. Vol. 28, No. 4, December 1996) for instructive material on the history of computer science.

${ }^{13}$ The complement to this process was the commitment by firms to make computers available at heavily discounted prices and provide complementary inputs to academics (Rosenberg, 1983).
} 
Bio-informatics (Ouzounis and Valencia, 2003), Management Information Systems (Davis, 2006), and Biotechnology (Arora and Gambardella, 1995).

To conclude, just as technological regimes undergo various stages, so disciplines evolve progressively out of different shapes of technology and modes of engaging it. The tension between "practical versus abstract" orientations of engineering disciplines as recounted by Noble (1977) is a fitting instantiation of this. In the second half of the 1800s, highly specialized training on narrow tasks was the only feasible response to novel demand for expertise in nascent areas such as wood distillation or electric wiring. Accordingly, the core of technical education revolved around design principles and "how to" type of content still closely matching the direct handling of the technology. Progressively however, the absorption of roundabout techniques, "electrification" and "chemicalization" (sic: 16), by established craftindustries entailed the disruption of old ways and the transformation of production routines. As the respective technologies entered unforeseen domains of use, user industries demanded more skilled workers, but of a different kind. The content of electrical and chemical engineering training in the early 1900s exhibits a higher level of abstraction, more scientific content, and while previous cohorts were hired as skilled technicians, the new generations went on to become managers of the user industries. Thereby, the cyclical tension between applied and theoretical recounted by Braverman (1974) and Noble (1977) is but a reflection of the skill life-cycle: at early stages of a transition know-how is strongly tied to the technical, still tacit, specifications but as soon as learned practice enhances the ability to extract standardized rules and instructions, the core content of education moves toward a more abstract content.

\section{Discussion and policy implications}

In this section, we explore some macro implications of the proposed life-cycle framework and offers suggestions for future empirical research. A key aspect of our skill life-cycle concerns the extent to which differences in knowledge systematization affect the cross-country differences in performance and the evolution of labor market inequalities. In relation to the first issue, each country maintains relative advantage through reliance on an institutional configuration that favors the re-absorption of routinized mismatches. Thus, for example, the tradition in Germany is to combine vocational and on-the-job training, against the backdrop of a regulated labor market. Another possibility is a system that relies on quick and decentralized responses by formal education, as in the USA. Highly decentralized systems that rely heavily on formal educational institutions, such as in the USA, allow more room for experimentation and, thus, better conditions to cope with radical skill mismatches and novel technological problems. According to Baumol (2004), flexible and diversified teaching styles help to explain the higher creativity and productivity 
of US scientists with respect to their European counterparts. Greater room for experimentation in education may be a source of comparative advantage-especially in phases where potential innovations are more radical and general purpose. ${ }^{14}$ Recent work on the impact of ICTs for employment and productivity points to the key role of the US higher education system in explaining the better performance of the USA with respect to central European countries (e.g. Krueger and Kumar, 2004; Amendola and Vona, 2012).

A more decentralized education system, more open to experimentation, such as in the USA, might speed up the process of knowledge systematization (Murnane and Nelson, 1984) at the cost of higher levels of heterogeneity across education institutions. Consistent with this is evidence of a relatively fatter tail on the right-hand side of the US skill distribution (Freeman and Schettkat, 2001). ${ }^{15}$ As a result of this asymmetric adjustment to training programs to respond to new technological requirements, skills dispersion will increase more in highly decentralized education systems. Overall, taking account of adaptations to the supply of education sheds light on the trade-off between the speed of acquisition and the degree heterogeneity in the effective skills related to specific qualifications.

Increased heterogeneity in effective skills following the advent of ICT technologies has been the driving force behind the increase of income inequality in the USA (Juhn et al., 1993; Autor et al., 2008). ${ }^{16}$ The structural imbalances between job complexity and existing education programs highlight two empirical "anomalies" in wage inequality dynamics. First, the onset of the ICT revolution in the early 1970s produced a decline in the college premium, associated with a substantial increase in within-group wage dispersion, i.e., the residual inequality not explained by observable characteristics such as qualifications, experience, gender, etc. From the early 1980s, the trend reversed and the college wage premium overcame its initial decline and increased steadily. However, within-group residual inequality did not return to its pre-ICT level, especially in top occupations and for high educational levels (Autor et al., 2008). Thus, the initial decrease in the college premium reflects an obsolescence effect associated with the decreasing utility of existing education programs

\footnotetext{
${ }^{14}$ The conventional wisdom in work by Nelson and Phelps (1966) and Hall and Soskice (2001) suggests that institutional mechanisms favoring the development of general skills lead to successful radical innovation, compared to systems where the workforce is characterized by specific skills. However, the empirical evidence is mixed, but the USA remains an outlier in terms of the capacity to produce path-breaking innovation (e.g. Akkermans et al., 2009).

${ }^{15}$ Empirical evidence based on the standardized skills of the workforce (IALS survey) shows that the average skills level is higher in Germany than in the USA, and that in the USA, the variance in the skills distribution is characterized by two fat tails around the 25th and 75th percentiles (Freeman and Schettkat, 2001).

${ }^{16}$ The USA is a good example since in unregulated labor markets, the wage is expected to depend more directly on workers' effective skills.
} 
vis-à-vis new skill requirements, and especially highly paid jobs whose skill-content has been relatively more affected by the uptake of ICTs (Eckstein and Nagypal, 2004; Autor et al., 2008).

To reiterate the life-cycle metaphor, at the beginning of a technological revolution new knowledge and skills stemming from innovative processes are sticky and tacit, and mostly outside of the established knowledge domain; thus, the importance of formal education decreases and the relative comparative advantages from using the new technologies are reserved to a few early users and are mostly unobservable empirically. In turn, the persistent increase in within-group wage inequality, especially among graduates (Eckstein and Nagypal, 2004), likely stems from heterogeneous adjustments to the supply of higher education which underlies the US's leadership in innovation. Note that, unless opportunities to access new education programs are unfairly distributed across individuals, competition among workers with similar educational attainments eventually will squeeze the wage premia earned by early users of new technologies. However, if cycles of knowledge creation and systematization are limited to elite institutions, i.e. those that collaborate closely with highly innovative sectors, a gap in the quality of education is likely to become a persistent source of within-graduate wage inequality. ${ }^{17}$ This arguably illustrates the generality of the skill life-cycle heuristic.

Let us conclude by offering some reflections on policy aspects. No doubt, skill development is an uncertain endeavor because the pace and the extent of the transformations in labor markets accelerated the obsolescence of existing know-how and the emergence of skill gaps (Mason, 2011). As we have seen, formal education institutions may have a comparative advantage in this adjustment, but only when the adjustment is decentralized and at the cost of increasing heterogeneity in educational supply and hence higher inequalities. In more centralized policy environments (e.g. France, Scandinavian countries), changes in skill demands have to be monitored, articulated, and translated into updated curricula that can soon become obsolete and for which there is little time for experimentation and adjustment. Policy makers often struggle with problems whose boundaries change rapidly and the creation of large-scale repositories, like the skill content at the workplace $\mathrm{O}^{\star} \mathrm{NET}$, helps in redirecting policy efforts at all levels. But uncertainty has another important connotation in terms of co-ordination of adjustment both across government layers and among different actors. The dichotomy between incremental and radical

\footnotetext{
${ }^{17}$ Two complementary pieces of evidence support this argument. First, the persistent increase in the graduate wage premium and wage dispersion in the college cohort (or higher) are strongly correlated to a substantial increase in the post-graduate wage premium (Eckstein and Nagypal, 2004); second, evidence on the relation between university quality and earnings (e.g. Brewer et al., 1999) shows that the fraction of the graduate wage premium explained by university quality increased sharply between the 1970s and the 1990s. However, Black et al. (2005) find a constant wage premium for elite institutions between 1987 and 1998.
} 
adjustment is in fact mostly theoretical: as long as specific and general training are complementary, successful adjustments require inputs from a broad range of fields encompassing education as well as science and technology, labor markets, industrial policies, migration and public finance. Creating linkages and feedback mechanisms across these different realms is essential for ensuring efficiency and minimizing duplication of efforts (Carneiro and Heckman, 2003). The issue of coordination extends also to the level of individual organizations type and employers. This, in turn, calls for a climate that nurtures skill development by offering incentives to invest in learning to both individuals and employers (O'Connell and Jungblut, 2008; Desjardins and Warnke, 2012).

\section{Concluding remarks}

This essay has drawn on work in economics and history to untangle the relationship between skills and the emergence of new technological paradigms. It has highlighted several important issues overlooked by the human capital and innovation studies literature. In our view, the former ignores the emergence of skills mismatches in a dynamic context where technology and education mutually adapt, while the latter is still lacking a thorough articulation of the role of human capital and labor market dynamics in the process of technological change. The article bridges these two streams by emphasizing the role of institutions for the systematization of knowledge. Our life-cycle heuristic articulates the emergence, development, and transformation of the content and conduits of the transmission of new knowledge and skills. Accordingly, we capture two crucial phases of a stylized skill-innovation life-cycle. On the one hand, we describe the disruptive effects of technological change on the organization of work, typically consisting in either new task configurations within existing occupations or in new occupations. On the other hand, we appreciate in historical perspective the role of qualitative adjustments to education and training. Contrary to existing literature, we do not propose that spurred by radical new technology the education system launches into a relentless catching up with a static frontier. Rather, repeated practice with new technology improves work performance and, the gradual standardization of new skills for the purpose of diffusion may or may not open up new opportunities by facilitating the translation of that technology to unforeseen contexts of use.

The exploratory ideas presented in this article seek to call attention to the opportunity for innovation scholars to pursue a research agenda on the interrelations among innovation, labor markets, and the dynamics of knowledge creation, and diffusion. Accordingly we propose two immediate directions for future research based on the framework elaborated here. The first focuses on fine-grained occupational characteristics (provided by the Dictionaries of Occupations and Titles) and could track changes in the skill requirements of occupations within different sectors. 
This would contribute to explaining cross-sectoral specificities and longitudinal changes in the skills bases within sectors affected differently by technological change along the lines of recent studies (Consoli and Elche-Hortelano, 2010; Consoli et al, 2013). A second research direction would focus on how academic disciplines evolve in response to the impulse of innovation, and how changes in course content within universities are associated with the quality of higher education institutions - measured by patents rather than adoption of ICT capital. If the process of systematization is as relevant as we expect occupations with higher exposure to radical innovations should experience a stronger reconfiguration of their skill content, and the educational programs associated to them should change more rapidly. We hope that this article provides a solid base for the pursuit of such an agenda.

\section{Acknowledgements}

The authors are grateful to Cristiano Antonelli, William Baumol, Jean Luc Gaffard, Maurizio Iacopetta, Stan Metcalfe, Dick Nelson, Francesco Rentocchini, and Richard Wooley for thought-provoking comments on earlier drafts. The authors would also like to thank the editor and three anonymous referees for providing us with stimulating suggestions. The authors states all errors and omissions as their own.

\section{Funding}

DC gratefully acknowledges Financial supports from the European Commission (FP7-PEOPLE-IEF-2008-235278).

\section{References}

Acemoglu, D. and D. Autor (2010), 'Skills, tasks and technologies: implications for employment and earnings,' NBER Working Papers 16082.

Acemoglu, D. and J. S. Pischke (1999), 'Beyond becker: training in imperfect labor markets,' Economic Journal, 109, F112-F142.

Aghion, P. and P. Howitt (2004), 'Appropriate growth policy: a unified framework,' Journal of the European Economic Association, 4, 269-314.

Aghion, P., P. Howitt and L. Violante (2002), 'General purpose technology and within-group wage inequality,' Journal of Economic Growth, 7, 315-345.

Akkermans, D., C. Castaldi and B. Los (2009), 'Do 'liberal market economies' really innovate more radically than 'coordinated market economies'?: hall and soskice reconsidered,' Research Policy, 38(1), 181-191. 
Allen, J. and R. van der Velden (2001), EducationalMismatches Versus Skill Mismatches: Effects on Wages, Job-related Training, and On-the-job Search, Vol. 3, Oxford Economic Papers, pp. 434-452.

Amendola, M. and J. L. Gaffard (1988), The Innovative Choice: An Economic Analysis of the Dynamics of Technology. Basil Blackwell: Oxford, UK.

Amendola, M. and F. Vona (2012), 'Coordinating the accumulation of physical and human capital in different institutional settings,' Economics of Innovation and New Technology, 21, 631-653.

Arora, A. and A. Gambardella (1995), 'Division of innovative labour in biotechnology,' in N. Rosenberg and A. Gelijns (eds), University-Industry Interface and Medical Innovation. National Academy of Sciences: Washington DC.

Arthur, W. B. (2009), The Nature of Technology: What it Is and How it Evolves. The Free Press: New York.

Atack, J., F. Bateman and R. A. Margo (2004), 'Skill intensity and rising wage dispersion in nineteenth-century American manufacturing,' The Journal of Economic History, 64(1), $172-192$.

Autor, D., F. Levy and R. Murnane (2003), 'The skill content of recent technological change: an empirical exploration,' Quarterly Journal of Economics, 118, 1279-1333.

Autor, D., L. Katz and M. Kearney (2006), 'The polarization of the U.S. labor market,' American Economic Review, 96, 189-194.

Autor, D. H., L. F. Katz and M. S. Kearney (2008), 'Trends in U.S. wage inequality: revising the revisionists,' The Review of Economics and Statistics, 90(2), 300-323.

Balconi, M., A. Pozzali and R. Viale (2007), 'The "Codification Debate” revisited: a conceptual framework to analyze the role of tacit knowledge in economics,' Industrial and Corporate Change, 16(5), 823-849.

Baumol, W. J. (2002), The Free Market Innovation Machine. Princeton University Press: Princeton.

Baumol, W. J. (2004), 'Education for innovation: entrepreneurial breakthroughs vs. corporate Incremental Improvements,' NBER Working Paper 10578.

Becker, G. (1993), Human Capital: A Theoretical and Empirical Analysis, with Special Reference to Education. Chicago University Press: Chicago.

Black, D. A., D. Kermit and J. A. Smith (2005), 'College Quality and Wages in the United States,' German Economic Review, 6(3), 415-443.

Braverman, H. (1974), Labor and Monopoly Capital: The Degradation of Work in the Twentieth Century. Monthly Review Press: New York.

Bresnahan, T. and M. Trajtenberg (1995), 'General purpose technologies 'Engines of growth'?' Journal of Econometrics, 65(1), 83-108.

Brewer, D., E. Eide and R. Ehrenberg (1999), 'Does it pay to attend an elite private college? Cross-cohort evidence on the effects of college type on earnings,' Journal of Human Resources, 34, 104-123. 
Brynjolfsson, E. and L. Hitt (2000), 'Beyond computation: information technology, organization transformation and business performance,' Journal of Economic Perspectives, 14(4), 23-48.

Brynjolfsson, E. and A. McAfee (2014), The Second Machine Age: Work, Progress and Prosperity in a Time of Brilliant Technologies. Norton \& Co.: New York, NY.

Busemeyer, M. (2009), 'Asset specificity, institutional complementarities and the variety of skill regimes in coordinated market economies,' Socio-Economic Review, 7(3), 375-406.

Butera, F. (2014), 'Automation,' in J. Wright (ed.), International Encyclopaedia of Social and Behavioral Sciences. Elsevier: Oxford.

Carneiro, P. and J. Heckman (2003), 'Human capital policy,' in J. heckman and A. krueger (eds), Inequality in America: What Role for Human Capital Policy? MIT Press: Cambridge, MA.

Caselli, F. (1999), 'Technological revolutions,' American Economic Review, 89, 78-102.

CEDEFOP (2010), Employer-provided Vocational Training in Europe: Evaluation and Interpretation of the Third Continuing Vocational Training Survey. Publications Office of the European Union.

Chandler, A. D. (1977), The Visible Hand. Cambridge, Mass. and London. The Belknap Press: England.

Consoli, D. (2005), 'The dynamics of technological change in UK retail banking services: an evolutionary perspective,' Research Policy, 34(4), 461-480.

Consoli, D., F. Vona and F. Rentocchini (2013), 'That was then, this is now: skills and routinization in the 2000s,' INGENIO Working Paper.

Consoli, D. and D. Elche Hortelano (2010), 'Variety in the knowledge base of knowledge intensive business services,' Research Policy, 39(10), 1303-1310.

Cowan, R., P. A. David and D. Foray (2000), 'The explicit economics of knowledge codification and tacitness,' Industrial and Corporate Change, 9, 211-253.

David, P. A. (2001), 'Path dependence, its critics, and the quest for 'historical economics', in P. Garrouste and S. Ioannides (eds), Evolution and Path Dependence in Economic Ideas: Past and Present. Edward Elgar: London.

David, P. A. and G. Wright (1997), 'Increasing returns and the genesis of American resource abundance,' Industrial and Corporate Change, 6(2), 203-245.

David, P. A. and G. Wright (2003), 'General purpose technologies and productivity surges: historical reflections on the future of the ICT revolution,' in P. A. David and M. Thomas (eds), The Economic Future in Historical Perspective. Oxford University Press for the British Academy: Oxford.

Davis, G. (2006), 'Information systems as an academic discipline,' in D. Avison, S. Elliot, J. Krogstie and J. Pries-Heje (eds), The Past and Future of Information Systems: 1976-2006 and Beyond. Springer: Boston, pp. 11-25.

Desjardins, R. and A. Warnke (2012), 'Ageing and skills: a review and analysis of skill gain and skill loss over the lifespan and over time,' OECD Education Working Papers, No. 72. 
Di Pietro, G. and P. Urwin (2006), 'Education and skills mismatch in the Italian graduate labour market,' Applied Economics, 38, 79-93.

Eckstein, Z. and É. Nagypál (2004), 'The evolution of U.S. earnings inequality: 1961-2002,' Quarterly Review (December), 28, 10-29.

Estevez-Abe, M., T. Iversen and D. Soskice (2001), 'Social protection and the formation of skills: a reinterpretation of the welfare state,' in P. A. Hall and D. W. Soskice (eds), Varieties of Capitalism: The Institutional Foundations of Comparative Advantage. Oxford University Press: Oxford.

Filippetti, A. (2010), 'Harnessing the 'essential tension' of design: the complex relationship between the firm and designer consultant', Italian National Research Council, Rome. pp. 1-22.

Freeman, C. and C. Perez (1988), 'Structural crises of adjustment, business cycles and investment behavior,' in G. Dosi, C. Freeman, R. R. Nelson, G. Silverberg and L. Soete (eds), Technical Change and Economic Theory. Pinter: London.

Freeman, R. and R. Schettkat (2001), 'Skill compression, wage differentials, and employment: Germany vs the US,' Oxford Economic Papers, 53(3), 582-603.

Galor, O. and J. Zeira (1993), 'Income distribution and macroeconomics,' Review of Economic Studies, 60, 35-52.

Galor, O., O. Moav and D. Vollrath (2009), 'Inequality in landownership, the emergence of human-capital promoting institutions, and the great divergence,' Review of Economic Studies, 76(1), 143-179.

Geuna, A. (1999), The Economics of Knowledge Production: Funding and the Structure of University Research. Edward Elgar: Cheltenham, UK; Northampton, MA, USA.

Goldin, C. and L. Katz (1999), 'The shaping of higher education: the formative years in the United States, 1890 to 1940,' Journal of Economic Perspectives, 13(1), 37-62.

Goldin, C. and L. Katz (2008), The Race Between Education and Technology. Harvard University Press: Harvard.

Goos, M. and A. Manning (2007), 'Lousy and lovely jobs: the rising polarization of work in Britain,' Review of Economics and Statistics, 89, 118-133.

Gray, R. (2013), 'Taking technology to task: the skill content of technological change in early twentieth century United States,' Explorations in Economic History, 50(3), 351-367.

Green, F. and S. McIntosh (2007), 'Is there a genuine under-utilization of skills amongst the over-qualified?' Applied Economics, 39, 427-439.

Hall, P. A. and D. W. Soskice (eds) (2001), Varieties of Capitalism: The Institutional Foundations of Comparative Advantage. Oxford University Press: Oxford.

Harayama, Y. (1998), Private Incentive and the Role of Government in Technology Advancement: Silicon Valley, Stanford University and The Federal Government. University of Geneva: Mimeo.

Hughes, T. (1983), Networks of Power: Electrification in Western Society, 1880-1930. John Hopkins University Press. 
Houston, D. (2005), 'Employability, skills mismatch and spatial mismatch in metropolitan labour markets,' Urban Studies, 42, 221-243.

Iacopetta, M. (2010), 'Phases of economic development and the transitional dynamics of an innovation-education growth model,' European Economic Review, 54(2), 317-330.

Juhn, C., K. M. Murphy and B. Pierce (1993), 'Wage inequality and the rise in returns to skill,' Journal of Political Economy, 101(3), 410-442.

Kodama, F. (1995), Emerging Patterns of Innovation: Sources of Japan's Technological Edge. Harvard Business Press.

Krueger, D. and K. Kumar (2004), 'U.S.-Europe differences in technology-driven growth: quantifying the role of education,' Journal of Monetary Economics, 51, 161-190.

Kyvik, S. (2004), 'Structural changes in higher education systems in Western Europe,' Higher Education in Europe, 24(3), 393-409.

Langlois, R. (2003), 'Cognitive comparative advantage and the organization of work: lessons from Herbert Simon's vision of the future,' Journal of Economic Psychology, 24, 167-187.

Lazonick, W. (1990), Competitive Advantage on the Shop Floor. Harvard University Press.

Levy, F. and R. Murnarne (2004), The New Division of Labor. Princeton University Press: New York, NY.

Lundvall, B. A. and B. Johnson (1994), 'The Learning Economy,' Industry \& Innovation, 1(2), 23-42.

Mason, G. (2011), 'Product strategies, skills shortages and skill updating needs in England: new evidence from the National Employer Skills Survey. Report No. 30', UK Commission for Employment and Skills. London.

Metcalfe, J. S. (2002), 'The development of economic ideas in relation to capital goods,' CoPS Working Paper 99.

Mowery, D. and R. Langlois (1996), 'Spinning off and spinning on(?): the federal government role in the development of the US computer software industry,' Research Policy, 25, 947-966.

Mowery, D. C. (2010), 'Federal policy and the development of semiconductors, computer hardware, and computer software: a policy model for climate change R \& D?, in R. M. Henderson and R. G. Newell (eds), Accelerating Energy Innovation: Insights from Multiple Sectors. National Bureau of Economic Research Inc, pp. 159-188.

Murnane, R. and R. Nelson (1984), 'Production and innovation when techniques are tacit: the case of education,' Journal of Economic Behavior and Organization, 5, 353-373.

Nelson, R. (1994), 'The co-evolution of technology, industrial structure and supporting institutions,' Industrial and Corporate Change, 3, 47-63.

Nelson, R. and E. Phelps (1966), 'Investments in human capital, technological diffusion, and economic growth,' American Economic Review, 56, 69-75.

Nelson, R. and S. Winter (1982), An Evolutionary Theory of Economic Change. Harvard University Press: Cambridge, MA. 
Nightingale, P. (2000), 'The product-process organization relationship in complex development projects,' Research Policy, 29, pp 913-930.

Noble, D. F. (1977), America by Design: Science, Technology and the Rise of Corporate Capitalism. Knopf: New York, NY.

Norgaard, R. L. (1981), 'The evolution of business finance textbooks,' Financial Management, 10(2), 36-47.

O'Connell, P. and J. M. Jungblut (2008), 'What do we know about training at work?,' in K. U. Mayer and H. Solga (eds), Skill Formation: Interdisciplinary and Cross-National Perspective. Cambridge University Press: Cambridge, England.

Organization for Economic Cooperation and Development (OECD) (2009), Education at Glance. OECD: Paris.

Ouzounis, C. A. and A. Valencia (2003), 'Early bioinformatics: the birth of a discipline,' Bioinformatics, 19, 2176-2190.

Paulinyi, A. (1986), 'Revolution and technology,' in R. Porter and M. Teich (eds), Revolution in History. Cambridge University Press: Cambridge, England.

Pissarides, C. (2000), Equilibrium Unemployment Theory. MIT Press: Cambridge, MA, US.

Rosenberg, N. (1976), Perspectives on Technology. Cambridge University Press: Cambridge, England.

Rosenberg, N. (1998), 'Chemical engineering as a general purpose technology,' in E. Helpman (ed.), General Purpose Technologies and Economic Growth. MIT: Cambridge MA, pp. 167-192.

Rosenberg, N. and R. R. Nelson (1994), 'American universities and tecnica advance in industry,' Research Policy, 23(3), 323-348.

Rosenberg, N. and W. E. Steinmueller (2013), 'Engineering knowledge,' Industrial and Corporate Change, 22, 1129-1158.

Rosenberg, R. (1983), 'American physics and the origins of electrical engineering,' Physics Today, 36(10), 48-54.

Sattinger, M. (1993), 'Assignment models of the distribution of earnings,' Journal of Economic Literature, American Economic Association, 31, 831-880.

Simon, H. (1960), 'The corporation: will it be managed by machines?', in M. L. Anshen and G. L. Bach (eds), Management and the Corporations 1985. New York: McGraw-Hill, pp. 17-55.

Spitz-Oener, A. (2006), 'Technical change, job tasks and rising educational demands: looking outside the wage structure,' Journal of Labor Economics, 24, 235-270.

Sutherland, J. (2012), 'Qualifications mismatch and skills mismatch,' Education + Training, 54, 619-632.

Tether, B., A. Mina, D. Consoli and D. Gagliardi (2005), 'A Literature Re-view on Skills and Innovation. How Does Successful Innovation Impact on the Demand for Skills and How Do Skills Drive Innovation?', Report for the Department of Trade and Industry. London. 
Toner, O. (2011), 'Workforce skills and innovation: an overview of major themes in the literature,' OECD Science, Technology and Industry Working Papers with number 2011/1.

Vandenbussche, J., P. Aghion and C. Meghir (2006), 'Growth distance to the frontier and the composition of human capital,' Journal of Economic Growth, 11, 97-127.

Vincenti, W. G. (1990), What Engineers Know and How They Know It. Baltimore: Johns Hopkins University Press.

Whitley, R. (1988), 'The management sciences and managerial skills,' Organization Studies, 9(1), 47-68.

Wright, G. (1999), 'Can a nation learn? American technology as a network phenomenon,' in N. R. Lamoreaux, D. M. G. Raff and P. Temin (eds), Learning by Doing in Markets, Firms, and Countries. National Bureau of Economic Research, Inc.: Cambridge, MA, pp. 295-332.

Yoshikawa, H. (1993), 'Systematization of design knowledge,' Annals of the CIRP, 42, 131-134. 